\title{
Impact of the Co/Ni-Ratio on Microstructure, Thermophysical Properties and Creep Performance of Multi-Component $\gamma^{\prime}$-Strengthened Superalloys
}

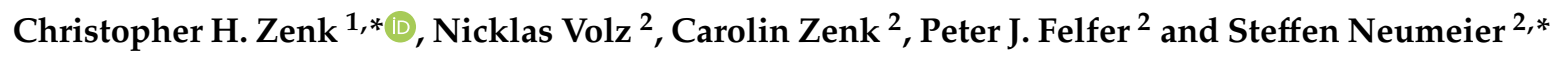 \\ 1 Department of Material Science and Engineering, Institute II, Friedrich-Alexander-Universität, \\ Erlangen-Nürnberg, Martensstr. 5a, 91058 Erlangen, Germany \\ 2 Department of Material Science and Engineering, Institute I, Friedrich-Alexander-Universität, \\ Erlangen-Nürnberg, Martensstr. 5a, 91058 Erlangen, Germany; nicklas.volz@fau.de (N.V.); \\ carolin.zenk@fau.de (C.Z.); peter.felfer@fau.de (P.J.F.) \\ * Correspondence: christopher.zenk@fau.de (C.H.Z.); steffen.neumeier@fau.de (S.N.)
}

Received: 14 October 2020; Accepted: 17 November 2020; Published: 21 November 2020

\begin{abstract}
The Ni content is a crucial factor for the development of $\gamma^{\prime}$-strengthened Co-based superalloys and some studies have systematically addressed its influence on various properties in model superalloys. In this paper, we report for the first time the influence of the $\mathrm{Co} / \mathrm{Ni}$ ratio in the more advanced nine-component superalloy ERBOCo-1: exchanging $\mathrm{Co}$ and $\mathrm{Ni}$ in this $\mathrm{Co} / \mathrm{Ni}$-based superalloy while keeping the other alloying elements constants has a big influence on a variety of material properties. The elemental segregation after casting is slightly more pronounced in the alloy with higher Ni-content. Microstructural characterization of this alloy termed ERBOCo-1X after heat-treatment reveals that the precipitates are cuboidal in the Co- and spherical in the Ni-rich alloy, indicating a decrease in the $\gamma / \gamma^{\prime}$ lattice misfit. Analyzing the elemental partitioning behavior by atom probe tomography suggests that the partitioning behavior of $\mathrm{W}$ is responsible for that. Furthermore, it is found that even though $\mathrm{Ni}$ exhibits the highest overall concentration, the $\gamma$ matrix phase is still Co-based, because $\mathrm{Ni}$ is strongly enriched in the $\gamma^{\prime}$ precipitates. Creep tests at $900^{\circ} \mathrm{C}$ reveal that even though the microstructure looks less favorable, the creep resistance of the Ni-rich alloy is slightly superior to the Co-rich variant.
\end{abstract}

Keywords: cobalt; nickel; superalloy; thermophysical properties; segregation; atom probe tomography; elemental partitioning; creep behavior

\section{Introduction}

Thermal engines for aviation and industrial gas turbines rely on materials that can withstand high mechanical stress and corrosive atmospheres at elevated temperatures. Today, the superalloys are the most famous class of materials that fulfill these requirements [1]. They are traditionally based on the Ni-Al binary system and derive their excellent combination of strength and ductility from a high-volume fraction of ordered intermetallic $\gamma^{\prime}$ precipitates $\left(\mathrm{L}_{2}\right.$ crystal structure, based on $\left.\mathrm{Ni}_{3} \mathrm{Al}\right)$ coherently embedded in a disordered face-centered cubic matrix. In the hottest section of turbines, they are used in single-crystalline form. Incremental alloy development has led to complex alloys with around ten alloying elements, carefully balancing properties such as the $\gamma^{\prime}$ volume fraction, the lattice misfit between the two phases, solid solution strengthening and diffusivity of the matrix phase, corrosion and oxidation behavior, etc. One of the major optimization goals was and continues to be the increase of the maximum service temperature with the associated benefits for the energy efficiency of thermal engines. However, in the $\sim 80$ years since the superalloys were first discovered, 
the continuous improvement has saturated and significant leaps in temperature capability of alloys based on Ni-Al seem unlikely.

In comparison to $\mathrm{Ni}$, Co has a $\sim 40{ }^{\circ} \mathrm{C}$ higher solidus temperature, which makes it an interesting base element as it has the potential to increase the service temperature of the thermal engines. However, a stable $\mathrm{Co}_{3} \mathrm{Al} \gamma^{\prime}$ phase does not exist in the corresponding binary system. Accordingly, conventional Co-based superalloys solely rely on solid solution and carbide strengthening, though they still represent a very valuable class of materials due to their hot-corrosion resistance, thermal fatigue resistance, workability, and weldability [2]. In the past decade, Co-based superalloys have gained significant attention in the scientific literature since the discovery of a $\mathrm{Co}_{3}(\mathrm{Al}, \mathrm{W}) \mathrm{L1}_{2}$ phase in 2006 enabled the utilization of $\gamma^{\prime}$ strengthening [3]. A large number of these studies focuses on the ternary Co-Al-W-alloys and the effect of quaternary alloying additions [4-9]. One major finding of many studies is that a certain amount of $\mathrm{Ni}$ in these alloys is required, mainly to increase the $\gamma^{\prime}$ solvus temperature and widen the $\gamma / \gamma^{\prime}$ phase region in composition space [6]. However, the influence of $\mathrm{Ni}$ on various alloy properties has only been addressed on the basis of alloys whose compositions differed in more than just the $\mathrm{Ni} / \mathrm{Co}$-content $[10,11]$ or in quaternary and quinary model superalloys $[6,12-14]$. Our own studies on five quinary Ni/Co-9Al-8W-8Cr alloys [12-15] show that:

- The elemental segregation on the dendrite scale is lower on the Co-rich side of the system.

- The $\gamma^{\prime}$ solvus temperature decreases with an increase of the Co content.

- Liquidus and solidus temperature remain largely unaffected.

- $\quad$ The $\gamma^{\prime}$ volume fraction exhibits a maximum in the alloy in which the Ni/Co-ratio is 1:3.

- The oxidation resistance at $900{ }^{\circ} \mathrm{C}$ strongly and monotonously increases with the amount of Ni present.

- The lattice misfit is negative on the Ni-rich side of the system (lattice parameter $\mathrm{a}_{0, \gamma^{\prime}}<\mathrm{a}_{0, \gamma}$ ) and positive on the Co-rich side $\left(\mathrm{a}_{0, \gamma^{\prime}}>\mathrm{a}_{0, \gamma}\right)$, with a zero-transition between $\mathrm{Ni} / \mathrm{Co}=3: 1$ and 1:1.

- The elemental partitioning between the $\gamma$ and $\gamma^{\prime}$ phases is much more pronounced on the Ni-rich side of the system. Elements are generally distributed more homogeneously between the two-phase in the Co-rich alloys (with the exception of W).

- The creep resistance (in terms of the minimum creep rate at $900{ }^{\circ} \mathrm{C}$ and $250 \mathrm{MPa}$ ) of the Ni-based alloy increases with the addition of $\mathrm{Co}$, reaches an optimum at $\mathrm{Ni} / \mathrm{Co}=3: 1$, and strongly deteriorates over two orders of magnitude with a further addition of $\mathrm{Co}$. However, the opposite effect was found for $\mathrm{Cr}$-free $\mathrm{Ni} / \mathrm{Co}-9 \mathrm{Al}-8 \mathrm{~W}$ alloys.

The present study aims at revealing whether these observed trends are also confirmed in multinary alloys that can be considered closer to application. The single crystalline Co-based alloy ERBOCo-1* has already been introduced in several publications $[16,17]$. Related Co-based superalloys with similar composition, but polycrystalline, fine-grained microstructure have been characterized in [18-21]. ( ${ }^{*}$ The acronym ERBOCo derives from the location of the two partner universities in the Deutsche Forschungsgemeinschaft (DFG) collaborative research center SFB/TR 103-Erlangen and Bochum-in the framework of which these alloys were developed.)

Additionally to $\mathrm{Co}$ and $\mathrm{Ni}$, ERBOCo- 1 contains $\mathrm{Al}$ and $\mathrm{W}$ to form the $\gamma^{\prime}$ phase, Ta and Ti to increase the $\gamma^{\prime}$ stability, volume fraction, and solvus temperature, $\mathrm{Si}$ and $\mathrm{Cr}$ to improve oxidation and corrosion resistance, and $\mathrm{Hf}$ for castability. The only difference between ERBOCo- 1 and ERBOCo- $1 \mathrm{X}$ is that their $\mathrm{Co} / \mathrm{Ni}$-contents have been exchanged so that the latter is a Ni-based alloy. As the $\mathrm{Co} / \mathrm{Ni}$ ratio is fairly close to unity ( $\sim 7 / 5$ and $\sim 5 / 7$, respectively), there is in fact no single base-element and both alloys must be considered $\mathrm{Co} / \mathrm{Ni}$-based superalloys.

\section{Experimental Procedures}

The nominal compositions of ERBOCo-1 and ERBOCo-1X are listed in Table 1. Both alloys were cast as single-crystalline (SX) rods in a laboratory-scale Bridgman-furnace using a withdrawal rate of $3 \mathrm{~mm} / \mathrm{min}$ after homogenizing the melt for $30 \mathrm{~min}$ at $1550{ }^{\circ} \mathrm{C}$. Prior to SX casting, the alloys have been 
arc-melted from master alloys with the composition of ERBOCo-1 and Co-20Al-20W (at.\%), and raw element granules of at least $99.9 \%$ purity.

Table 1. Nominal composition of alloys ERBOCo-1 and ERBOCo-1X in at.\%.

\begin{tabular}{cccccccccc}
\hline & Co & Ni & Al & Cr & W & Ti & Ta & Si & Hf \\
\hline ERBOCo-1 & 44.5 & 32 & \multirow{2}{*}{3} & 8 & 5 & 2.5 & 1.5 & 0.4 & 0.1 \\
ERBOCo-1X & 32 & 44.5 & 8 & 8 & & & & & \\
\hline
\end{tabular}

Segregation on the dendrite scale was determined by electron probe microanalysis (EPMA) area mappings employing a JXA 8100 instrument (JOEL, LTd. Tokyo, Japan).

Differential scanning calorimetry (DSC) measurements with heating/cooling rates of $10^{\circ} \mathrm{C} / \mathrm{min}$ were performed on the as-cast state in order to determine characteristic transformation temperatures such as liquidus and solidus temperatures. Based on these measurements, the two alloys underwent the same heat-treatment consisting of a solutionizing and homogenization step at $1280^{\circ} \mathrm{C}$ for $8 \mathrm{~h}$. $\mathrm{h}$ followed by two-step direct aging at $1050^{\circ} \mathrm{C}$ and $900{ }^{\circ} \mathrm{C}$ for $5 \mathrm{~h}$ and $16 \mathrm{~h}$, respectively. The heating and cooling rates between the individual segments was $5{ }^{\circ} \mathrm{C} / \mathrm{min}$. The DSC measurements were repeated in the heat-treated condition to produce a better signal for $\gamma^{\prime}$ solvus temperature.

The microstructure in the heat-treated condition was characterized by scanning electron microscopy (SEM) using a Cross Beam 1540EsB FIB/SEM system (Carl Zeiss AG, Oberkochen, Germany) following a standard metallographic sample preparation. Transmission electron microscopy (TEM) diffraction contrast imaging was performed on a CM200 (Koninklijke Philips N.V., Amsterdam, Netherlands). For that, samples were ground down to $\sim 100 \mu \mathrm{m}$ thickness and electrolytically thinned down to electron transparency using a TenuPol-5 electropolishing unit (Struers ApS, Ballerup, Denmark). The commercial electrolyte Struers A3 was kept at temperatures ranging from $-20{ }^{\circ} \mathrm{C}$ to $-5{ }^{\circ} \mathrm{C}$ during the polishing procedure.

The $\gamma$ and $\gamma^{\prime}$ compositions were determined by atom probe tomography (APT) following specimen preparation through focused ion beam milling in an Helios NanoLab 600i FIB Workstation (FEI, Hilsboro, Oregon, USA). The APT specimens were then field evaporated in a LEAP 4000X HR instrument (CAMECA SAS, Gennevilliers, France) at $\sim 55 \mathrm{~K}$ employing a pulse rate of $200 \mathrm{kHz}$ and a pulse fraction of $\sim 20 \%$. Proxigrams across the large $\gamma / \gamma^{\prime}$ interface in the center of the reconstruction were used to determine the phase compositions. As elemental enrichment or depletion is to be expected at the interface due to the finite cooling rate from the last heat-treatment segment, the composition of the individual phases was averaged in sub-volumes at least $5 \mathrm{~nm}$ from the interface.

Compressive creep experiments were conducted at $900{ }^{\circ} \mathrm{C}$ and a true stress of $250 \mathrm{MPa}$.

\section{Results and Discussion}

Superalloys based on the Co-Al-W ternary system have been suggested to exhibit excellent castability because of the lower degree of elemental segregation during solidification [22]. However, this conclusion was drawn from comparing simple ternary and quaternary model Co-based superalloys with advanced complex Ni-based superalloys. In a previous study, we had already shown that the degree of elemental segregation increases in multinary Co-based superalloys [23]. Comparing the as-cast state of ERBOCo-1 and ERBOCo-1X allows addressing the influence of only the Ni/Co-content on elemental segregation without the effect of further alloying elements which influence the solidification behavior. The elemental segregation after casting of ERBOCo-1 and ERBOCo- $1 \mathrm{X}$ single crystals, as determined by EPMA, is exemplarily shown for $\mathrm{W}$ in Figure 1 . W was chosen for representation as the mass density difference arising from its depletion in the melt can cause convective instabilities resulting in casting defects. In both cases, $\mathrm{W}$ is enriched in the dendrite core. Qualitatively, this enrichment appears to be more pronounced in the Ni-rich alloy ERBOCo-1X. 

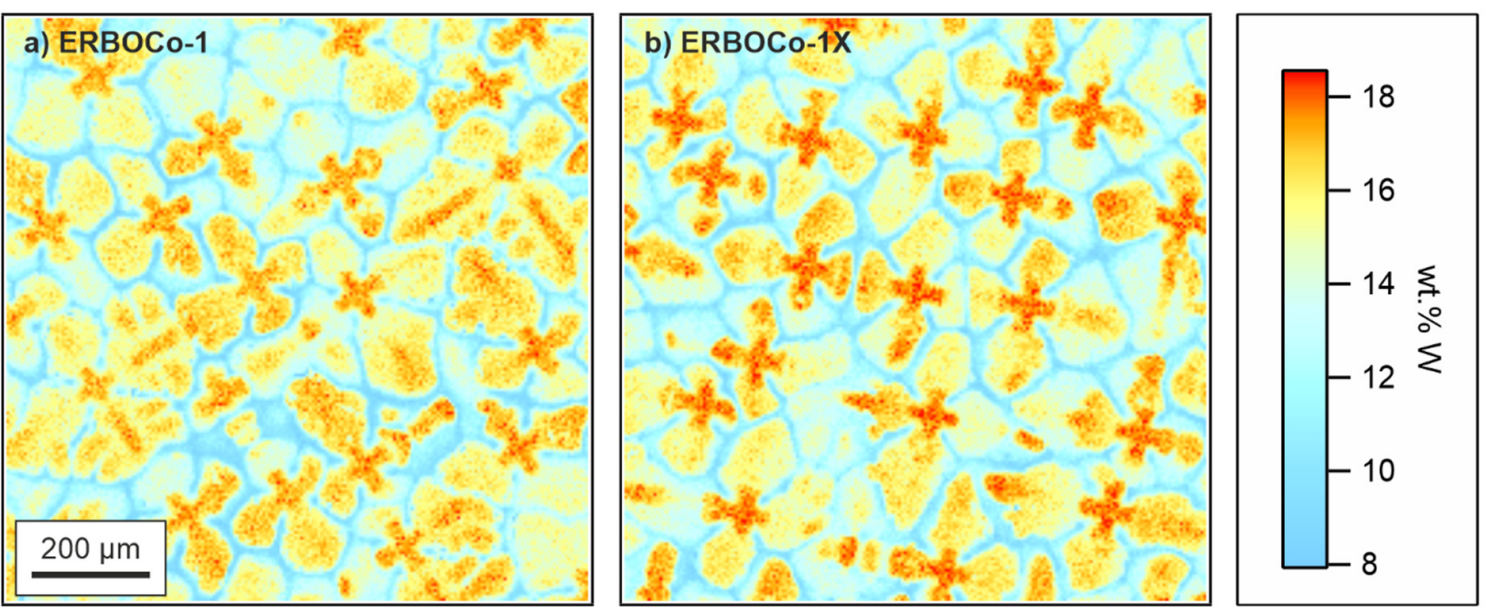

Figure 1. Tungsten segregation in the as-cast state as determined by electron probe microanalysis (EPMA): (a) ERBOCo-1 and (b) ERBOCo-1X.

Figure 2 shows a histogram of all the data in Figure 1 in addition to the data from equivalent EPMA mappings in the heat-treated condition. The distribution of $\mathrm{W}$-concentration values in the as-cast state is very asymmetric for both alloys. The main peak on the right-hand side corresponds to the dendrite cores and the shoulder on the left sides to the dendrite arms and interdendritic regions. Although there is indeed a higher W-concentration in the dendrite cores of ERBOCo- $1 \mathrm{X}$, the difference seems marginal and the concentration of the interdendritic regions (corresponding to the liquid solidifying last) is not affected much. Based on this simple approach, a major difference of castability in these alloys is not to be expected. As anticipated, the peak-widths in the histogram decrease after heat-treatment and assume a more symmetric shape. Even though homogeneity of both alloys clearly improved during heat treatment, it is evident that both still exhibit residual segregation so that dendrite cores and interdendritic regions differ by $\sim 4.5 \mathrm{wt} . \% \mathrm{~W}$ (corresponding to $\sim 1.7$ at.\%). The residual segregation is slightly higher in the Ni-rich alloy ERBOCo-1X as indicated by the lower and wider peak, but the difference is not significant. However, the distribution of $\mathrm{W}$ in both alloys seems sufficient to locally influence thermophysical properties such as $\gamma^{\prime}$ volume fraction, $\gamma / \gamma^{\prime}$ lattice misfit, and phase compositions with the associated consequences for mechanical properties.

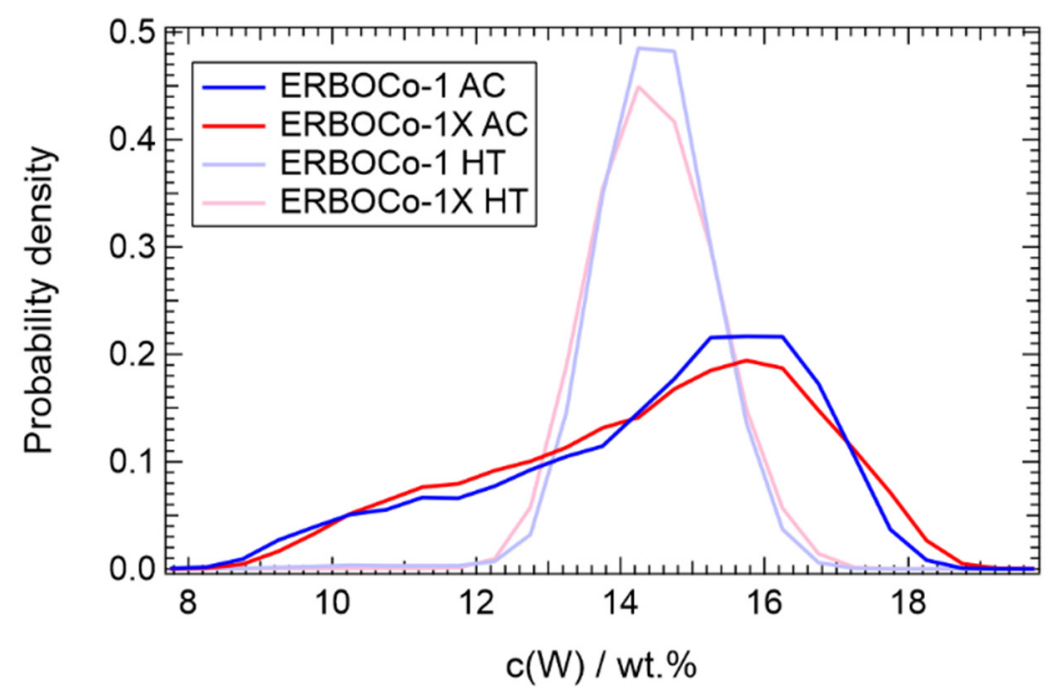

Figure 2. Histograms of the $\mathrm{W}$ concentrations in ERBOCo- 1 and ERBOCo- $1 \mathrm{X}$ in the as-cast (AC) and heat-treated (HT) conditions $\left(1280^{\circ} \mathrm{C} / 8 \mathrm{~h}+1050{ }^{\circ} \mathrm{C} / 5 \mathrm{~h}+900^{\circ} \mathrm{C} / 16 \mathrm{~h}\right)$. 
For $\gamma^{\prime}$ strengthened Ni/Co-9Al-8W and Ni/Co-9Al-8W-8Cr superalloys, we have reported that the $\gamma^{\prime}$ solvus temperature increases with the Ni-content, whereas solidus and liquidus temperatures remain largely unaffected $[12,13]$. As shown in Table 2, these trends remain the same in the multinary alloys ERBOCo-1 and ERBOCo-1X in the heat-treated condition. Taking into account the experimental measurement accuracy, no significant difference between the liquidus and solidus temperatures can be detected. The initial motivation-higher solidus temperatures of Co-based superalloys-can evidently not be retained in more complex alloys. Additionally, as already reported for model superalloys, it is confirmed that the higher Co-content results in a significantly lower $\gamma^{\prime}$ solvus temperature: it increases by $\sim 50^{\circ} \mathrm{C}$ from $1145^{\circ} \mathrm{C}$ in ERBOCo- 1 to $1195^{\circ} \mathrm{C}$ in ERBOCo- $1 \mathrm{X}$.

Table 2. Characteristic transformation temperatures in ${ }^{\circ} \mathrm{C}$ as determined from the heating segments from DSC measurements in the heat-treated condition.

\begin{tabular}{cccc}
\hline & Liquidus & Solidus & $\gamma^{\prime}$ Solvus \\
\hline ERBOCo-1 AC & 1420 & 1278 & - \\
ERBOCo-1X AC & 1417 & 1287 & - \\
ERBOCo-1 HT & 1423 & 1357 & 1145 \\
ERBOCo-1X HT & 1417 & 1355 & 1195 \\
\hline
\end{tabular}

The solidus and liquidus temperatures of ERBOCo-1 are $\sim 20-40{ }^{\circ} \mathrm{C}$ higher than previously published values $\left(1318{ }^{\circ} \mathrm{C}\right.$ and $\left.1400{ }^{\circ} \mathrm{C}\right)$. The reason for this remains unclear. The measurements in that study have been conducted in the as-cast state, which could explain a lower solidus temperature, but the liquidus temperature should remain unaffected by that. Another possible explanation is that, contrary to the present study, polycrystalline samples which had been arc-melted from raw elements (as opposed to the aforementioned master melt) were used for the DSC measurements-potentially with higher deviations from the nominal alloy composition. Furthermore, the higher heating rate used in the present study $\left(10{ }^{\circ} \mathrm{C} / \mathrm{min}\right.$ vs. $\left.5^{\circ} \mathrm{C} / \mathrm{min}\right)$ can shift the apparent transformation temperatures to higher temperatures. However, the opposite is found for the $\gamma^{\prime}$ solvus temperature, which was published to be $1174{ }^{\circ} \mathrm{C}, \sim 30^{\circ} \mathrm{C}$ higher than what we report here. As neither heat-treatment condition nor heating-rate can explain that, a deviation from the nominal alloy composition in the previous study seems the most likely explanation for the observed differences.

The microstructure of the two alloys after heat-treatment is shown in Figure 3. The back-scattered electron (BSE) micrographs reveal two striking differences between the alloys: a change of precipitate morphology and an inversion of the contrast. The former can be explained by a change of the lattice misfit. The lattice misfit $\delta$ of $\gamma^{\prime}$ strengthened superalloys is defined by

$$
\delta=\frac{a_{\gamma^{\prime}}-a_{\gamma}}{0.5\left(a_{\gamma^{\prime}}+a_{\gamma}\right)}
$$

and is typically negative for $\mathrm{Ni}$ - and positive for Co-based superalloys. To minimize strain energy, superalloys with a lattice misfit $|\delta|>0$ typically form cuboidal precipitates to minimize the strain energy by aligning the interfaces parallel to the elastically soft $<100>$ directions. The more spherical shape of the precipitates in ERBOCo-1X, as opposed to the cubic ones in ERBOCo-1, indicates that it exhibits a lower lattice misfit during aging. This is consistent with the findings in Ni/Co-Al-W-Cr model alloys, where an increase of the Ni-content caused a decrease of the positive lattice misfit and ultimately a zero-transition around the same $\mathrm{Ni} / \mathrm{Co}$ ratio as in ERBOCo- $1 \mathrm{X}$. The major reason for this phenomenon was found to be a change of the elemental partitioning behavior. The aforementioned contrast inversion in the BSE already gives a hint that a significant change of elemental partitioning behavior is to be expected in the present multinary alloys as well. 

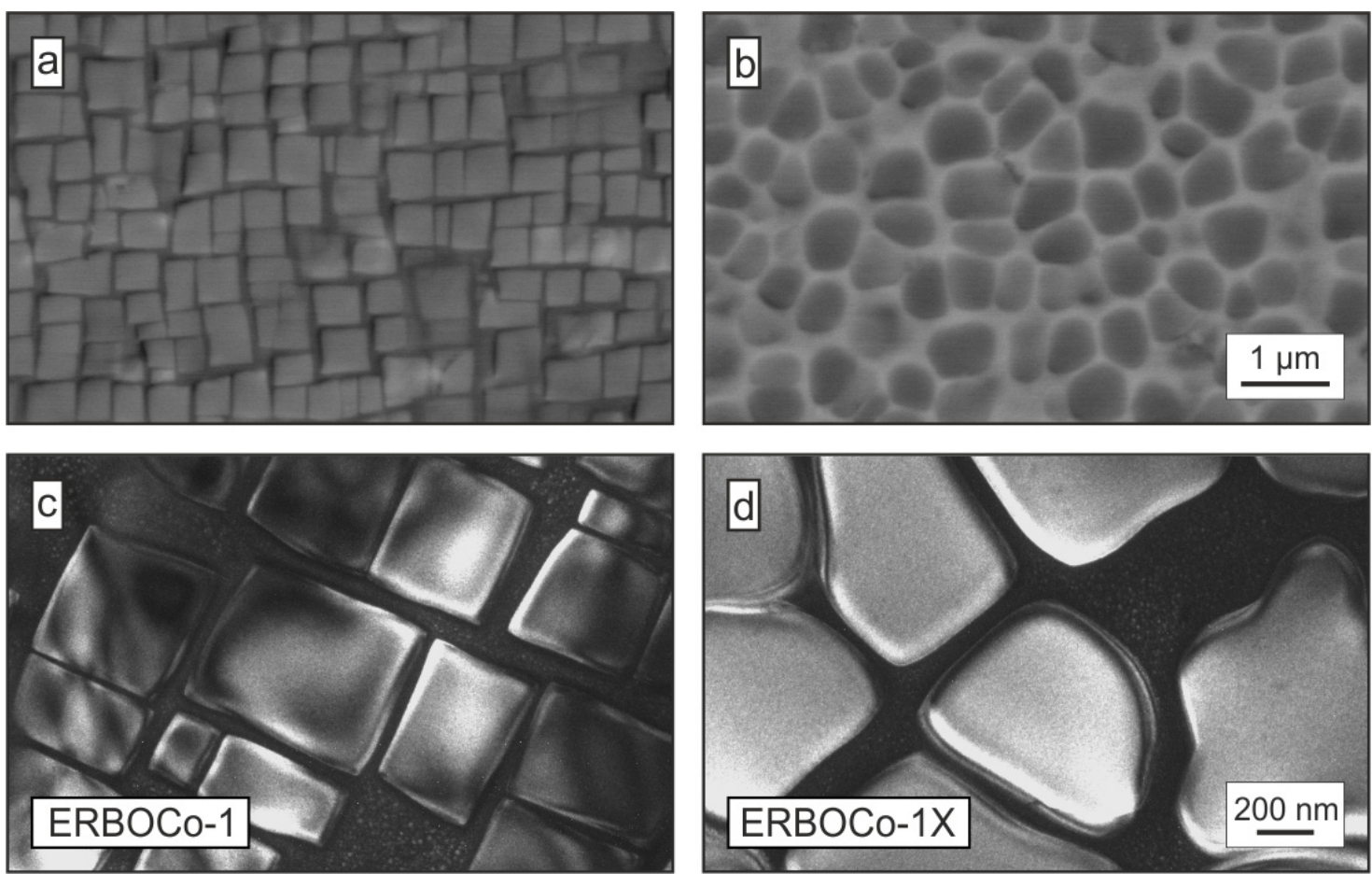

Figure 3. Scanning electron microscopy (SEM) back-scattered electron micrographs of (a) ERBOCo-1 and

(b) ERBOCo-1X and the corresponding transmission electron microscopy (TEM) dark-field micrographs

(c,d) along a $<100>$ zone axis employing a $001 \gamma^{\prime}$ superlattice reflection for imaging.

To further address this phenomenon, atom probe tomography was performed on specimens extracted from the dendrite cores of the heat-treated samples. The reconstructions of these APT specimens are shown in Figure 4. Al and $\mathrm{Cr}$ atoms were selected for representation. In both alloys, $\mathrm{Cr}$ is enriched in the disordered $\gamma$ matrix (left) and $\mathrm{Al}$ in the intermetallic $\gamma^{\prime}$ phase (right), but the enrichment seems to be more pronounced in the Ni-rich alloy ERBCo-1X. Additionally, the $\gamma$ phase contains tertiary $\gamma^{\prime}$ precipitates of $\sim 10 \mathrm{~nm}$ in size that formed during cooling from the last heat-treatment segment. These are also visible in the TEM dark field micrographs of Figure 3.

a ERBOCo-1

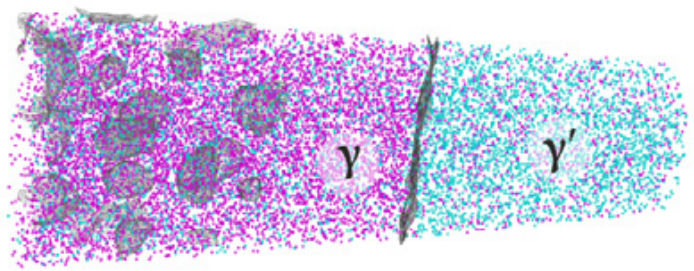

$10 \underline{\mathrm{nm}} \circ \mathrm{Al} \bullet \mathrm{Cr} \square$ iso 5 at.\% $\mathrm{Cr}$ b ERBOCo-1X

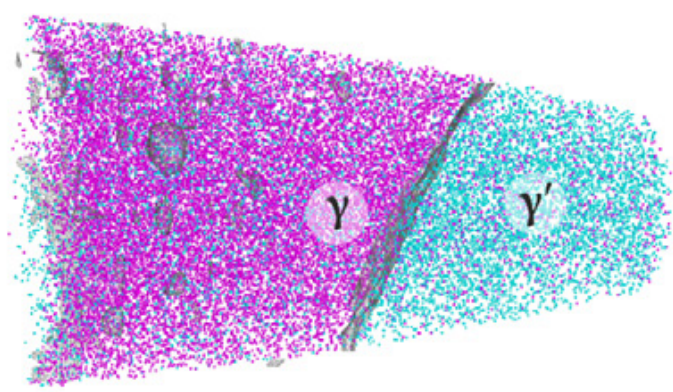

Figure 4. Atom probe tomography (APT) reconstructions of (a) ERBOCo-1 and (b) ERBOCo-1 showing $2 \%$ of the $\mathrm{Al}$ and $\mathrm{Cr}$ atoms and a $5 \% \mathrm{Cr}$ iso-concentration surface for visualization.

To determine the phase compositions, proximity histograms across the major $\gamma / \gamma^{\prime}$ interface in the center of the specimens were generated. As the phase composition at heat-treatment temperature were of interest, the tertiary precipitates were attributed to the $\gamma$ phase. The results are shown in Figure 5. The depletion or enrichment of solutes at or close to the $\gamma / \gamma^{\prime}$ phase results from the precipitates growing upon cooling and is not present at heat-treatment temperature, as we have shown before for model superalloys [24]. Due to these fluctuations, the average compositions of the individual phases 
have been determined in sub-volumes $5 \mathrm{~nm}$ away from the interface. The results are listed in Table 3. As it was the case for the Ni/Co-Al-W-Cr model alloys [13], the partitioning behavior of $\mathrm{W}$ is altered the most by an increase of the Ni-content: while enriched in $\gamma^{\prime}$ in ERBOCo-1, its concentration is slightly higher in $\gamma$ in the case of ERBOCo-1X. This change of partitioning behavior is considered the main reason for the contrast inversion of the back-scattered electron micrographs of Figure 3 and for the significant change of the precipitate morphology. The altered partitioning of the large $\mathrm{W}$-atoms causes an expansion of $\gamma$ and a contraction of $\gamma^{\prime}$ when $\mathrm{Ni}$ is added to the system and so reduces the positive lattice misfit to values closer to zero. The other elements generally retain their preferential partitioning behavior. As already mentioned above, $\mathrm{Al}$ and $\mathrm{Cr}$ are enriched more in their respective preferred phases in the alloy ERBOCo-1X with the higher Ni-content. Ti, Ta, and Hf qualitatively show the same partitioning behavior-toward $\gamma^{\prime}$ —in both alloys. However, all of them are slightly more enriched there in the Co-rich alloy ERBOCo-1. Ni and Co also retain their partitioning tendencies- $-\mathrm{Ni}$ to $\gamma^{\prime}$, Co to $\gamma$. However, it is noteworthy that the Co-content exceeds the Ni-content of both phases in ERBOCo-1. In contrast, the $\gamma$ phase of ERBOCo-1X exhibits a lower concentration of its base-element $\mathrm{Ni}$ in favor of Co.

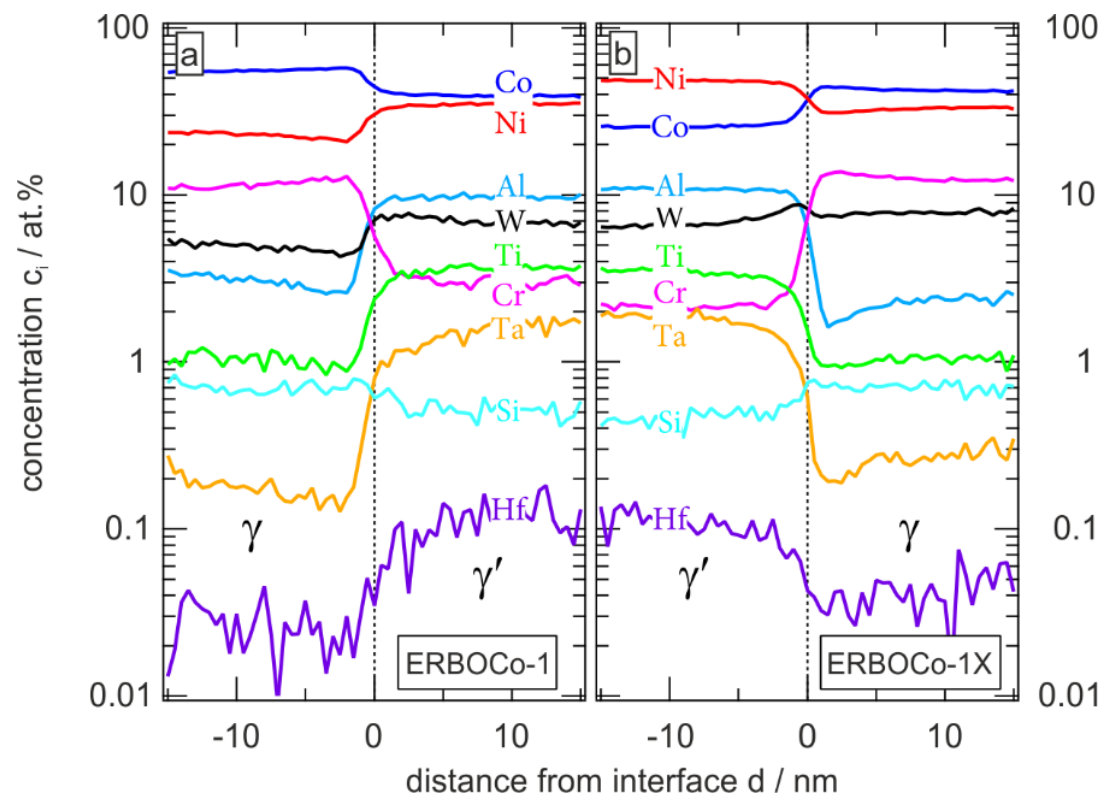

Figure 5. (a,b) Proximity histograms across the large $\gamma / \gamma^{\prime}$ interfaces shown in Figure 4a,b.

Table 3. Phase compositions in at.\% and partitioning coefficients of solutes in ERBOCo-1 and ERBOCo-1X after heat-treatment.

\begin{tabular}{ccccccc}
\hline & \multicolumn{3}{c}{ ERBOCo-1 } & \multicolumn{3}{c}{ ERBOCo-1X } \\
& $\gamma$ & $\gamma^{\prime}$ & $\mathbf{k}_{\gamma / \gamma^{\prime}}$ & $\boldsymbol{\gamma}$ & $\boldsymbol{\gamma}^{\prime}$ & $\mathbf{k}_{\gamma / \gamma^{\prime}}$ \\
\hline $\mathrm{Co}$ & 55.48 & 39.26 & 0.71 & 42.29 & 26.65 & 0.61 \\
$\mathrm{Ni}$ & 23.02 & 23.02 & 1.53 & 33.02 & 48.74 & 1.48 \\
$\mathrm{Al}$ & 3.11 & 9.76 & 3.13 & 2.34 & 10.91 & 4.65 \\
$\mathrm{Cr}$ & 11.47 & 3.01 & 0.26 & 12.45 & 2.14 & 0.17 \\
$\mathrm{~W}$ & 4.95 & 6.78 & 1.37 & 7.84 & 6.57 & 0.84 \\
$\mathrm{Ti}$ & 1.05 & 3.68 & 3.50 & 1.04 & 3.52 & 3.37 \\
$\mathrm{Ta}$ & 0.18 & 1.64 & 9.17 & 0.28 & 1.90 & 6.86 \\
$\mathrm{Si}$ & 0.70 & 0.52 & 0.73 & 0.71 & 0.47 & 0.66 \\
$\mathrm{Hf}$ & 0.03 & 0.13 & 4.58 & 0.04 & 0.12 & 2.63 \\
\hline
\end{tabular}

Ergo, ERBOCo-1X represents a superalloy with Ni-based $\gamma^{\prime}$ precipitates embedded in a Co-based $\gamma$ phase. This concept can indeed be very beneficial for the high-temperature creep properties: the $\gamma^{\prime}$ phase of Ni-based superalloys are reported to possess higher planar fault energies and consequently a 
higher resistance against dislocation shear [11]. Simultaneously, Co decreases the stacking fault energy of the matrix phase, which can impede recombination and cross-slip of partial dislocations [25-28]. The higher concentration of $\mathrm{Cr}$ and $\mathrm{W}$ in the matrix phase of ERBOCo-1X are expected to lower the stacking fault energy even further. Additionally, the diffusivity of solutes in Co is generally lower than in $\mathrm{Ni}$ [29] with the associated benefits for diffusion-controlled deformation.

Using a lever rule approach, the phase fractions can be determined based on the APT analysis:

$$
\begin{aligned}
& \vec{c}_{0}=\left(1-f_{m}\right) \times \vec{c}_{\gamma}+f_{m} \times \vec{c}_{\gamma} \\
& \left(\vec{c}_{0}-\vec{c}_{\gamma}\right)=f_{m} \times\left(\vec{c}_{\gamma^{\prime}}-\vec{c}_{\gamma}\right)
\end{aligned}
$$

where $f_{m}$ is the molar fraction of the $\gamma^{\prime}$ phase and the $\vec{c}_{i}$ are vectors in composition space containing the contents of the alloying elements in the nominal composition as entries. $\vec{c}_{0}$ is the nominal composition, $\vec{c}_{\gamma}$ and $\vec{c}_{\gamma^{\prime}}$ are the compositions of the $\gamma$ and $\gamma^{\prime}$ phases. Performing linear regression on Equation (3), yields the best fit for the $\gamma^{\prime}$ mole fraction $f_{m}$, which can be assumed to be equal to the $\gamma^{\prime}$ volume fraction $f_{v}$ because the number of atoms per volume is almost identical in the $\gamma$ and $\gamma^{\prime}$ phases (typically $|\delta|<1 \%$ ). The result is that the $\gamma^{\prime}$ volume fractions of ERBOCo- 1 and ERBOCo-1X are $70 \%$ and $68 \%$, respectively and thus-within the accuracy of this method $( \pm 3 \%)$-identical.

Compressive creep tests were conducted at $900{ }^{\circ} \mathrm{C}$ and a true stress of $250 \mathrm{MPa}$ up to a plastic strain of about $2 \%$. The results are shown in Figure 6. As can be seen in the strain vs. time curves of Figure 6a, ERBOCo-1X initially deforms faster, but it ultimately takes longer to reach the $\sim 2 \%$ plastic strain at which the tests were interrupted. This can be seen more clearly in Figure $6 \mathrm{~b}$ in which the creep rate is plotted as a function of the plastic strain. ERBOCo- 1 quickly approaches a local minimum creep rate at about $6 \times 10^{-9} \mathrm{~s}^{-1}$ before assuming a constant creep rate slightly higher than $10^{-8} \mathrm{~s}^{-1}$. The constant creep rate is surprising, as directional coarsening is expected to significantly alter the microstructure during creep deformation at $900{ }^{\circ} \mathrm{C}$. In contrast, the creep rate of ERBOCo- $1 \mathrm{X}$ slowly and steadily decreases to a level of $5.5 \times 10^{-9} \mathrm{~s}^{-1}$, slightly lower than the minimum creep rate of ERBOCo-1, and then starts to slightly increase again. The different shapes of the creep curves can be a result of a misorientation, which were $6^{\circ}$ and $9^{\circ}$ away from the [001] crystal direction for ERBOCo-1 and ERBOCo-1X, respectively, or indicate a change of the acting deformation mechanisms. Solely based on the micrographs in Figure 3, better creep properties of alloy ERBOCo-1 would be expected as a cubic $\gamma^{\prime}$ morphology and narrow $\gamma$ channels are considered beneficial. The tertiary $\gamma^{\prime}$ precipitates do not play a role as they would not be stable at the creep temperature, which is identical to the last heat-treatment segment. As the $\gamma^{\prime}$ volume fractions of the two alloys are nearly identical, a combination of higher solid solution strengthening, lower diffusivity and stacking fault energy of the $\gamma$ matrix, and a higher shear resistance of the precipitates are surmised to be the reason for the lower secondary creep rate despite a less favorable microstructure:

The deformation of Ni-based superalloys in the deformation regime at intermediate temperature and stresses is typically governed by $a / 2<110>$ type dislocations and largely limited to the $\gamma$ phase so that solid solution strengthening and diffusion in the matrix phase play an important role for mechanical performance [30]. W and Ta are the most potent solid solution strengthening elements in the present system. Provided the plastic deformation in ERBOCo- 1 and ERBOCo-1X is actually governed by dislocation glide in the matrix phase, the higher content of both these solutes in the matrix phase of ERBOCo-1X (Figure 5) might explain its lower secondary creep rate. W is a slowly diffusing element as well and impedes diffusional processes that allow dislocations to climb and bypass precipitates. Even though the overall diffusion of $\mathrm{W}$ is slightly slower in Co than in $\mathrm{Ni}$, their higher concentration in the matrix of the Ni-rich alloy ERBOCo-1X seems to be more advantageous with respect to mechanical performance [29,31]. 

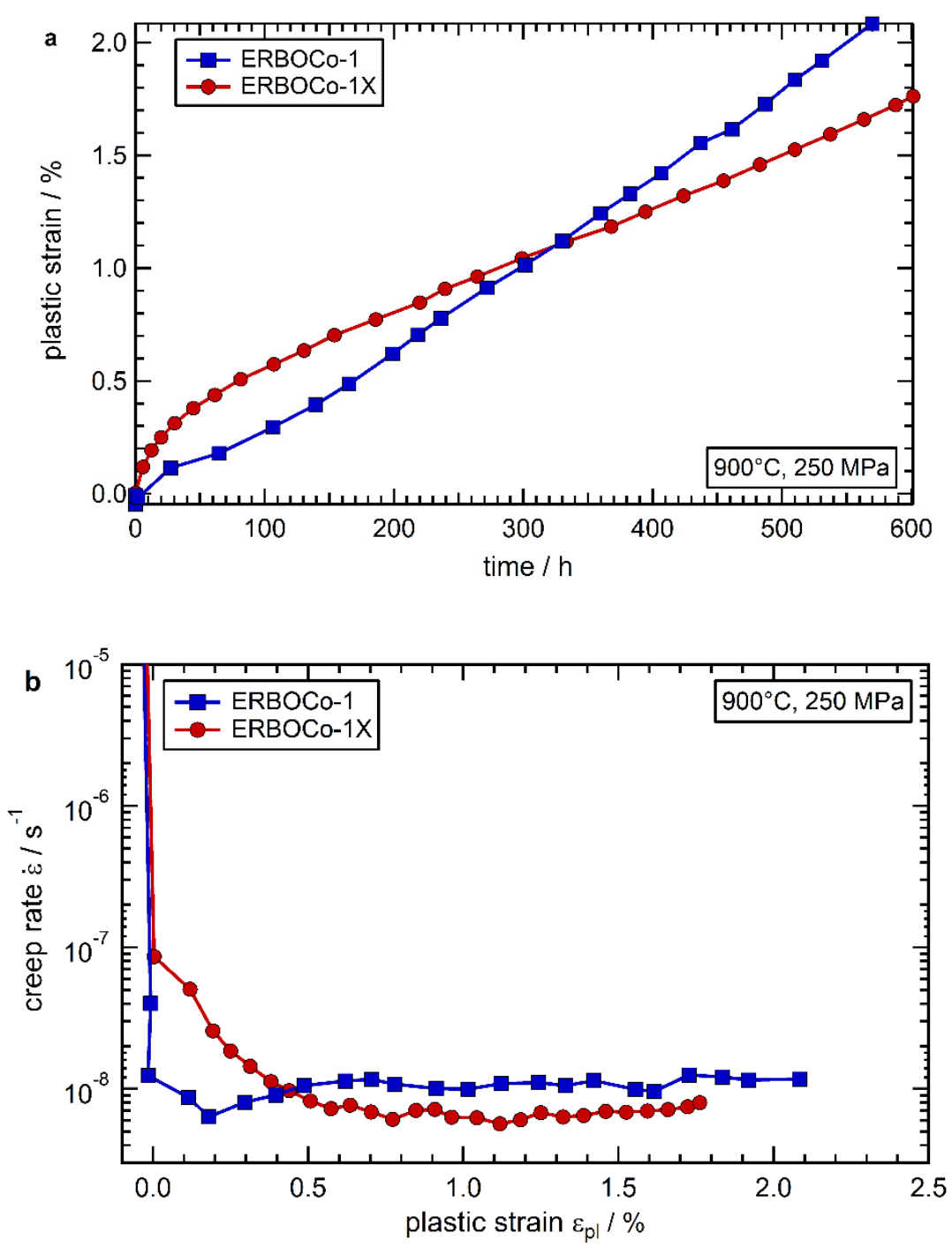

Figure 6. Compressive creep properties of ERBOCo- 1 and ERBOCo- $1 \mathrm{X}$ at $900^{\circ} \mathrm{C}$ and $250 \mathrm{MPa}$ : (a) plastic strain as a function of time, (b) creep rate as a function of plastic strain.

The stacking fault energy of the matrix phase is another property that will influence the deformation mode of the two alloys under investigation: a low stacking fault energy can be beneficial for creep as it impedes the recombination of dissociated dislocation segments, which is necessary for cross-slip [25-27]. Even though Co inherently has a much lower stacking fault energy than Ni [28], the altered partitioning behavior of elements that reduce ( $\mathrm{Cr}$ and $\mathrm{W}$ concentrations are higher in the ERBOCo-1X matrix) or increase ( $\mathrm{Al}$ concentration is lower in the ERBOCo-1X matrix) the stacking fault energy might tip the scales in favor of ERBOCo-1X.

These considerations are only valid if the deformation is actually governed by plasticity of the matrix phase. However, this is only the case if the resistance of the $\gamma^{\prime}$ precipitates against dislocation shear is sufficiently high. That this might not be the case in intermediate $\mathrm{Co} / \mathrm{Ni}$-based superalloys was, for example, shown in [11,32] where precipitates were sheared early on under the formation of different extended planar faults. At slightly lower temperatures and higher compressive stress $\left(850^{\circ} \mathrm{C}\right.$, $400 \mathrm{MPa}$ ), this was also observed for ERBOCo-1, where a significant number of precipitates were sheared under the formation of superlattice extrinsic stacking faults, which later developed into twins. In the same paper and a more recent study, very different mechanisms were discovered upon tensile loading [33]. 
Ultimately, the discussion of the creep response of ERBOCo-1 and ERBOCo-1X provided here are speculative until a detailed analysis of their deformation mechanisms is available.

\section{Summary and Conclusions}

This study characterizes two multinary $\gamma^{\prime}$ strengthened superalloys with respect to their microstructure as well as their thermophysical and mechanical properties. The alloys only differ in their $\mathrm{Co}$ and Ni contents which were 44.5 at.\% and 32 at.\% in ERBOCo- 1 and the reverse -32 at. $\%$ and 44.5 at.\%-in ERBOCo-1X, i.e., ERBOCo-1 is a Co-based and ERBOCo-1X a Ni-based alloys. It was found that:

- Elemental segregation during casting was slightly more pronounced in the Ni-based alloy ERBOCo-1X, although the differences were marginal.

- $\quad$ The addition of $\mathrm{Ni}$ at the expense of $\mathrm{Co}$ did not significantly alter the liquidus and solidus temperatures but increased the $\gamma^{\prime}$ solvus temperature by about $\sim 50{ }^{\circ} \mathrm{C}$.

- The $\gamma^{\prime}$ volume fraction remained largely unaffected by altering the Ni/Co-ratio and was found to be $\sim 70 \%$.

- The precipitate morphology was cubic in ERBOCo-1 and spherical in ERBOCo-1X, indicating a decrease of the positive lattice misfit with the addition of Ni.

- A reversion of the W partitioning (to $\gamma^{\prime}$ in ERBOCo-1 and $\gamma$ in ERBOCo-1X) was identified as the major reason for the change in lattice misfit.

- The partitioning behavior of $\mathrm{Al}\left(\right.$ to $\left.\gamma^{\prime}\right)$ and $\mathrm{Cr}$ (to $\gamma$ ) to their respective phases becomes more pronounced as the Ni-content was increased. Contrarily, Ta, Ti and Hf were more enriched in $\gamma^{\prime}$ in the Co-rich alloy ERBOCo-1.

- The Ni and Co partitioning of ERBOCo-1X caused the precipitates to be Ni-based whereas the matrix was Co-based.

- The shape of the compressive creep curves differed significantly, indicating a change of deformation mechanisms.

- The Ni-based superalloy ERBOCo-1X exhibited a lower secondary creep rate despite a less favorable microstructure.

All of the trends that were previously established for quaternary and quinary model superalloys were confirmed for the compositionally more complex alloys ERBOCo- 1 and ERBOCo-1X. The concept of Ni-based precipitates embedded within a Co-based matrix could potentially be exploited for alloy development, as the combination of higher precipitate planar fault energies and lower matrix stacking fault energy is expected to yield promising creep properties.

Author Contributions: C.H.Z.: Conceptualization, Methodology \& Investigation (EPMA, DSC, SEM, creep), Validation, Data curation, Visualization, Writing — original draft \& editing. N.V.: Methodology \& Investigation (SEM, TEM, creep), Visualization, Writing-revision \& editing. C.Z.: Methodology \& Investigation (APT), Visualization, Writing —revision \& editing. P.J.F.: Resources, Methodology (APT), Writing—revision, Supervision. S.N.: Conceptualization, Funding acquisition, Project administration, Supervision, Writing—revision \& editing. All authors have read and agreed to the published version of the manuscript.

Funding: This research was funded by the Deutsche Forschungsgemeinschaft (DFG) through projects B3 and Z01 of the collaborative research center SFB/TR 103, which also funded the APC.

Acknowledgments: Peter Randelzhofer (Institute II) and Sabine Michel (Institute II) are gratefully acknowledged for conducting the DSC and EPMA measurements, respectively.

Conflicts of Interest: The authors declare no conflict of interest.

\section{References}

1. Reed, R.C. The Superalloys; Cambridge University Press: Cambridge, UK, 2006; ISBN 9780511541285.

2. Beltran, A.M. Co-base alloys. In Superalloys II; Sims, C.T., Stoloff, N.S., Hagel, W.C., Eds.; John Wiley \& Sons, Inc.: Hoboken, NJ, USA, 1987; pp. 135-164. ISBN 0471011479. 
3. Sato, J.; Omori, T.; Oikawa, K.; Ohnuma, I.; Kainuma, R.; Ishida, K. Cobalt-base high-temperature alloys. Science 2006, 312, 90-91. [CrossRef] [PubMed]

4. Miura, S.; Ohkubo, K.; Mohri, T. Mechanical properties of co-based $\mathrm{L}_{2}$ intermetallic compound $\mathrm{Co}_{3}\left(\mathrm{Al}_{1} \mathrm{~W}\right)$. Mater. Trans. 2007, 48, 2403-2408. [CrossRef]

5. Suzuki, A.; Pollock, T.M. High-temperature strength and deformation of $\gamma / \gamma^{\prime}$ two-phase Co-Al-W-base alloys. Acta Mater. 2008, 56, 1288-1297. [CrossRef]

6. Shinagawa, K.; Omori, T.; Sato, J.; Oikawa, K.; Ohnuma, I.; Kainuma, R.; Ishida, K. Phase Equilibria and Microstructure on $\gamma^{\prime}$ Phase in Co-Ni-Al-W System. Mater. Trans. 2008, 49, 1474-1479. [CrossRef]

7. Ooshima, M.; Tanaka, K.; Okamoto, N.L.; Kishida, K.; Inui, H. Effects of quaternary alloying elements on the $\gamma^{\prime}$ solvus temperature of $\mathrm{Co}-\mathrm{Al}-\mathrm{W}$ based alloys with $\mathrm{fcc} / \mathrm{L} 1_{2}$ two-phase microstructures. J. Alloys Compd. 2010, 508, 71-78. [CrossRef]

8. Zhu, J.; Titus, M.S.; Pollock, T.M. Experimental Investigation and Thermodynamic Modeling of the Co-Rich Region in the Co-Al-Ni-W Quaternary System. J. Phase Equilibria Diffus. 2014. [CrossRef]

9. Zenk, C.H.; Neumeier, S.; Stone, H.J.; Göken, M. Mechanical properties and lattice misfit of $\gamma / \gamma^{\prime}$ strengthened Co-base superalloys in the Co-W-Al-Ti quaternary system. Intermetallics 2014, 55, 28-39. [CrossRef]

10. Eggeler, Y.M.; Titus, M.S.; Suzuki, A.; Pollock, T.M. Creep deformation-induced antiphase boundaries in $\mathrm{L1}_{2}$-containing single-crystal cobalt-base superalloys. Acta Mater. 2014, 77, 352-359. [CrossRef]

11. Titus, M.S.; Eggeler, Y.M.; Suzuki, A.; Pollock, T.M. Creep-induced planar defects in $\mathrm{L1}_{2}$-containing Co- and CoNi-base single-crystal superalloys. Acta Mater. 2015, 82, 530-539. [CrossRef]

12. Zenk, C.H.; Neumeier, S.; Engl, N.M.; Fries, S.G.; Dolotko, O.; Weiser, M.; Virtanen, S.; Göken, M. Intermediate $\mathrm{Co} / \mathrm{Ni}$-base model superalloys-Thermophysical properties, creep and oxidation. Scr. Mater. 2016, 112, 83-86. [CrossRef]

13. Zenk, C.H.; Neumeier, S.; Kolb, M.; Volz, N.; Fries, S.G.; Dolotko, O.; Povstugar, I.; Raabe, D.; Göken, M. The role of the base element in $\gamma^{\prime}$ strengthened cobalt/nickel-base superalloys. In Proceedings of the Superalloys 2016; John Wiley \& Sons, Inc.: Hoboken, NJ, USA, 2016; Volume 2016-Janua, pp. 969-980.

14. Volz, N.; Zenk, C.H.; Halvaci, T.; Matuszewska, K.; Neumeier, S.; Göken, M. Castability and Recrystallization Behavior of $\gamma^{\prime}$-Strengthened Co-Base Superalloys. In Superalloys; Springer: Cham, Switzerland, 2020; pp. 901-908.

15. Weiser, M.; Galetz, M.C.; Zschau, H.E.; Zenk, C.H.; Neumeier, S.; Göken, M.; Virtanen, S. Influence of Co to $\mathrm{Ni}$ ratio in $\gamma^{\prime}$-strengthened model alloys on oxidation resistance and the efficacy of the halogen effect at $900{ }^{\circ}$ C. Corros. Sci. 2019, 156, 84-95. [CrossRef]

16. Volz, N.; Zenk, C.H.; Cherukuri, R.; Kalfhaus, T.; Weiser, M.; Makineni, S.K.; Betzing, C.; Lenz, M.; Gault, B.; Fries, S.G.; et al. Thermophysical and Mechanical Properties of Advanced Single Crystalline Co-base Superalloys. Metall. Mater. Trans. A Phys. Metall. Mater. Sci. 2018, 49, 4099-4109. [CrossRef]

17. He, J.; Zenk, C.H.; Zhou, X.; Neumeier, S.; Raabe, D.; Gault, B.; Makineni, S.K. On the atomic solute diffusional mechanisms during compressive creep deformation of a Co-Al-W-Ta single crystal superalloy. Acta Mater. 2020, 184, 86-99. [CrossRef]

18. Neumeier, S.; Freund, L.P.P.; Göken, M. Novel wrought $\gamma / \gamma^{\prime}$ cobalt base superalloys with high strength and improved oxidation resistance. Scr. Mater. 2015, 109, 104-107. [CrossRef]

19. Freund, L.P.; Messé, O.M.D.M.; Barnard, J.S.; Göken, M.; Neumeier, S.; Rae, C.M.F. Segregation assisted microtwinning during creep of a polycrystalline $\mathrm{L} 1_{2}$-hardened Co-base superalloy. Acta Mater. 2017, 123, 295-304. [CrossRef]

20. Freund, L.P.; Giese, S.; Schwimmer, D.; Höppel, H.W.; Neumeier, S.; Göken, M. High temperature properties and fatigue strength of novel wrought $\gamma / \gamma^{\prime}$ Co-base superalloys. J. Mater. Res. 2017, 32, 4475-4482. [CrossRef]

21. Freund, L.P.; Stark, A.; Pyczak, F.; Schell, N.; Göken, M.; Neumeier, S. The grain boundary pinning effect of the $\mu$ phase in an advanced polycrystalline $\gamma / \gamma^{\prime}$ Co-base superalloy. J. Alloys Compd. 2018, 753, 333-342. [CrossRef]

22. Tsunekane, M.; Suzuki, A.; Pollock, T.M. Single-crystal solidification of new Co-Al-W-base alloys. Intermetallics 2011, 19, 636-643. [CrossRef]

23. Koßmann, J.; Zenk, C.H.; Lopez-Galilea, I.; Neumeier, S.; Kostka, A.; Huth, S.; Theisen, W.; Göken, M.; Drautz, R.; Hammerschmidt, T. Microsegregation and precipitates of an as-cast Co-based superalloy-Microstructural characterization and phase stability modelling. J. Mater. Sci. 2015, 50, 6329-6338. [CrossRef] 
24. Povstugar, I.; Choi, P.-P.; Neumeier, S.; Bauer, A.; Zenk, C.H.; Göken, M.; Raabe, D. Elemental partitioning and mechanical properties of Ti- and Ta-containing Co-Al-W-base superalloys studied by atom probe tomography and nanoindentation. Acta Mater. 2014, 78, 78-85. [CrossRef]

25. Sherby, O.D.; Burke, P.M. Mechanical behavior of crystalline solids at elevated temperature. Prog. Mater. Sci. 1968, 13, 323-390. [CrossRef]

26. Mukherjee, A.K.; Bird, J.E.; Dorn, J.E. Experimental Correlations for High-Temperature Creep. 1968. Available online: https://escholarship.org/uc/item/31p4z5v2 (accessed on 20 November 2020).

27. Mohamed, F.A.; Langdon, T.G. The transition from dislocation climb to viscous glide in creep of solid solution alloys. Acta Metall. 1974, 22, 779-788. [CrossRef]

28. Gallagher, P.C.J. The influence of alloying, temperature, and related effects on the stacking fault energy. Metall. Trans. 1970, 1, 2429-2461. [CrossRef]

29. Neumeier, S.; Rehman, H.U.; Neuner, J.; Zenk, C.H.; Michel, S.; Schuwalow, S.; Rogal, J.; Drautz, R.; Göken, M. Diffusion of solutes in fcc cobalt investigated by diffusion couples and first principles kinetic Monte Carlo. Acta Mater. 2016, 106, 304-312. [CrossRef]

30. Pollock, T.M.; Argon, A.S. Directional coarsening in Nickel-base single crystals with high volume fractions of coherent precipitates. Acta Met. Mater. 1994, 42, 1859-1874. [CrossRef]

31. Karunaratne, M.S.A.; Carter, P.; Reed, R.C. Interdiffusion in the face-centred cubic phase of the Ni-Re, Ni-Ta and Ni-W systems between 900 and $1300 \backslash^{\circ} \mathrm{C}$. Mater. Sci. Eng. A 2000, 281, 229-233. [CrossRef]

32. Eggeler, Y.M.; Müller, J.; Titus, M.S.; Suzuki, A.; Pollock, T.M.; Spiecker, E. Planar defect formation in the $\gamma^{\prime}$ phase during high temperature creep in single crystal CoNi-base superalloys. Acta Mater. 2016, 113, 335-349. [CrossRef]

33. Lenz, M.; Wu, M.; He, J.; Makineni, S.K.; Gault, B.; Raabe, D.; Neumeier, S.; Spiecker, E. Atomic Structure and Chemical Composition of Planar Fault Structures in Co-Base Superalloys. In Superalloys; Springer: Cham, Switzerland, 2020; pp. 920-928.

Publisher's Note: MDPI stays neutral with regard to jurisdictional claims in published maps and institutional affiliations.

(C) 2020 by the authors. Licensee MDPI, Basel, Switzerland. This article is an open access article distributed under the terms and conditions of the Creative Commons Attribution (CC BY) license (http://creativecommons.org/licenses/by/4.0/). 